Research article

Open Access

\title{
Role of STAT4 polymorphisms in systemic lupus erythematosus in a Japanese population: a case-control association study of the STAT1-STAT4 region
}

\author{
Aya Kawasaki1 ${ }^{1}$ Ikue Ito', Koki Hikami1, Jun Ohashi ${ }^{1}$, Taichi Hayashi², Daisuke Goto², \\ Isao Matsumoto2 ${ }^{2}$ Satoshi Ito ${ }^{2}$, Akito Tsutsumi2,3, Minori Koga4, Tadao Arinami4, \\ Robert R Graham ${ }^{5}$, Geoffrey Hom ${ }^{5}$, Yoshinari Takasaki ${ }^{6}$, Hiroshi Hashimoto ${ }^{6}$, \\ Timothy W Behrens ${ }^{5}$, Takayuki Sumida ${ }^{2}$ and Naoyuki Tsuchiya ${ }^{1}$
}

\author{
${ }^{1}$ Molecular and Genetic Epidemiology Laboratory, Doctoral Program in Life System Medical Sciences, Graduate School of Comprehensive Human \\ Sciences, University of Tsukuba, 1-1-1 Tennodai, Tsukuba 305-8575, Japan \\ 2Division of Clinical Immunology, Doctoral Program in Clinical Sciences, Graduate School of Comprehensive Human Science, University of Tsukuba, \\ 1-1-1 Tennodai, Tsukuba 305-8575, Japan \\ ${ }^{3}$ Department of Medicine, Takikawa Municipal Hospital, 2-2-34 Omachi, Takikawa 073-0033, Japan \\ ${ }^{4}$ Department of Medical Genetics, Doctoral Program in Life System Medical Sciences, Graduate School of Comprehensive Human Sciences, \\ University of Tsukuba, 1-1-1 Tennodai, Tsukuba 305-8575, Japan \\ ${ }^{5}$ Genentech, Inc., 1 DNA Way, South San Francisco, CA 94080, USA \\ ${ }^{6}$ Division of Rheumatology, Department of Internal Medicine, 2-1-1 Hongo, Bunkyo-ku, Tokyo 113-8421, Japan
}

Corresponding author: Naoyuki Tsuchiya, tsuchiya-tky@umin.ac.jp

Received: 15 Aug 2008 Revisions requested: 5 Sep 2008 Revisions received: 16 Sep 2008 Accepted: 19 Sep 2008 Published: 19 Sep 2008

Arthritis Research \& Therapy 2008, 10:R113 (doi:10.1186/ar2516)

This article is online at: http://arthritis-research.com/content/10/5/R113

(C) 2008 Kawasaki et al.; licensee BioMed Central Ltd.

This is an open access article distributed under the terms of the Creative Commons Attribution License (http://creativecommons.org/licenses/by/2.0), which permits unrestricted use, distribution, and reproduction in any medium, provided the original work is properly cited.

\begin{abstract}
Introduction Recent studies identified STAT4 (signal transducers and activators of transcription-4) as a susceptibility gene for systemic lupus erythematosus (SLE). STAT1 is encoded adjacently to STAT4 on 2q32.2-q32.3, upregulated in peripheral blood mononuclear cells from SLE patients, and functionally relevant to SLE. This study was conducted to test whether STAT4 is associated with SLE in a Japanese population also, to identify the risk haplotype, and to examine the potential genetic contribution of STAT1. To accomplish these aims, we carried out a comprehensive association analysis of 52 tag single nucleotide polymorphisms (SNPs) encompassing the STAT1-STAT4 region.
\end{abstract}

Methods In the first screening, 52 tag SNPs were selected based on HapMap Phase II JPT (Japanese in Tokyo, Japan) data, and case-control association analysis was carried out on 105 Japanese female patients with SLE and 102 female controls. For associated SNPs, additional cases and controls were genotyped and association was analyzed using 308 SLE patients and 306 controls. Estimation of haplotype frequencies and an association study using the permutation test were performed with Haploview version 4.0 software. Population attributable risk percentage was estimated to compare the epidemiological significance of the risk genotype among populations.

Results In the first screening, rs7574865, rs11889341, and rs10168266 in STAT4 were most significantly associated $(P<$ 0.01). Significant association was not observed for STAT1. Subsequent association studies of the three SNPs using 308 SLE patients and 306 controls confirmed a strong association of the rs7574865T allele (SLE patients: 46.3\%, controls: $33.5 \%, P=4.9 \times 10^{-6}$, odds ratio 1.71$)$ as well as TTT haplotype (rs10168266/rs11889341/rs7574865) $(P=1.5 \times$ $\left.10^{-6}\right)$. The association was stronger in subgroups of SLE with nephritis and anti-double-stranded DNA antibodies. Population attributable risk percentage was estimated to be higher in the Japanese population (40.2\%) than in Americans of European descent (19.5\%).

Conclusions The same STAT4 risk allele is associated with SLE in Caucasian and Japanese populations. Evidence for a role of STAT1 in genetic susceptibility to SLE was not detected. The contribution of STAT4 for the genetic background of SLE may be greater in the Japanese population than in Americans of European descent.

anti-dsDNA: anti-double-stranded DNA; Cl: confidence interval; IFN: interferon; IL: interleukin; IRF5: interferon regulatory factor-5; JPT: Japanese in Tokyo, Japan; LD: linkage disequilibrium; OR: odds ratio; PAR\%: population attributable risk percentage; RR: relative risk; SLE: systemic lupus erythematosus; SNP: single nucleotide polymorphism; STAT: signal transducers and activators of transcription. 


\section{Introduction}

Systemic lupus erythematosus (SLE) is a complex disease characterized by autoantibody production and involvement of multiple organs, including kidneys. Both genetic and environmental factors contribute to the development of SLE [1]. Until now, several genes have been reported to be associated with SLE, of which interferon regulatory factor-5 (IRF5) has been identified as a susceptibility gene common to multiple populations [2-6]. Recently, association of STAT4 (signal transducers and activators of transcription-4) haplotype tagged by rs7574865T with SLE was demonstrated in Caucasians [7]. Subsequently, two genome-wide association studies [8,9], a study focused on the STAT4 region in Caucasians [10], and replication studies in Colombians [11] and a Japanese population [12] have confirmed the association. In addition, an association of STAT4 with SLE phenotypes such as anti-double-stranded DNA (anti-dsDNA) autoantibodies, renal disorder, and age at diagnosis was reported [10,13]. An association of rs7574865 with other autoimmune diseases such as rheumatoid arthritis and primary Sjögren syndrome has also been demonstrated $[7,11,12,14]$. The STAT4 gene encodes a transcription factor belonging to the STAT family expressed in lymphocytes, macrophages, and dendritic cells. STAT4 is essential for interleukin (IL)-12 signaling and induces interferon-gamma (IFN $\gamma$ ) production and Th1 differentiation [15]. STAT4 is also activated by type I IFNs (IFN $\alpha / \beta)$ [16]. Moreover, the requirement of STAT4 in IL-23-induced IL-17 production has been suggested [17]. Two isoforms of STAT4, STAT $4 \alpha$ and STAT $4 \beta$, are known [18]. Expression of STAT4 $\beta$, lacking the transactivation domain, did not appear to be affected by the STAT4 single nucleotide polymorphisms (SNPs) [13]. STAT1, another member of the STAT family, is activated by type I IFNs and IFN $\gamma$ and plays an important role in immune responses [19]. STAT1 has been reported to be upregulated in peripheral blood mononuclear cells from SLE patients and in kidneys of lupus mice with nephritis [20,21], suggesting that STAT1 may play a role in the pathogenesis of SLE. A possible role of SNPs in the STAT1-STAT4 region other than the haplotype tagged by rs7574865T has recently been excluded in Caucasians [10]. However, in view of substantial differences in disease-associated alleles among populations [2], such analysis should be performed in each population. In this study, we carried out a comprehensive association analysis of the STAT1-STAT4 region with SLE in a Japanese population by scanning 52 tag SNPs of the region encompassing STAT1 and STAT4.

\section{Materials and methods Patients and healthy controls}

Patients and controls were recruited at Juntendo University, the University of Tsukuba, and the University of Tokyo. All patients and healthy controls were unrelated Japanese per- sons living in the central part of Japan. Three hundred eight SLE patients (18 males and 290 females, average age $41.4 \pm$ 13.5 years) and 306 healthy individuals ( 119 males and 187 females, average age $32.6 \pm 9.8$ years) were studied. Diagnosis of SLE and classification of the patients into clinical subsets were carried out according to the American College of Rheumatology criteria for SLE [22]. There was no overlap in cases or controls between this study and the recently reported study in a Japanese population [12]. These studies were reviewed and approved by the research ethics committees of the University of Tsukuba, the University of Tokyo, and Juntendo University. Informed consent was obtained from all study participants.

\section{Association study}

Fifty-two tag SNPs in the STAT1-STAT4 region were selected with an $r^{2}$ threshold of 0.9 based on the HapMap Phase II JPT (Japanese in Tokyo, Japan) data. These tag SNPs captured 127 SNPs with a minor allele frequency of greater than or equal to 0.05 . First screening was performed in 105 Japanese female SLE patients and 102 female healthy controls using the GoldenGate SNP genotyping assay (Illumina, Inc., San Diego, CA, USA). For the three SNPs that exhibited significant association $(P<0.01)$, additional samples were genotyped using the TaqMan SNP Genotyping Assay (Applied Biosystems, Foster City, CA, USA), and association was examined in 308 SLE patients and 306 healthy individuals.

\section{Statistical analysis}

Association of each SNP was analyzed by chi-square test. Because of the replicative nature of this study, correction for multiple testing was not performed, and unadjusted $P$ values are shown. Haplotype frequency estimation and association analysis using the permutation test were performed with Haploview version 4.0 software (Broad Institute of MIT and Harvard, Cambridge, MA, USA). In the haplotype analysis, the genotype data for rs10168266, rs11889341, and rs7574865 were used and these SNPs were assumed to compose a single haplotype block. In the permutation test, only frequencies of haplotypes in this block were compared (that is, the 'Haplotypes in Blocks Only' option was used). Ten million permutations were performed. To test the significance of each SNP conditional on the genotypes of other SNPs, logistic regression analysis was performed under the additive model for the minor allele. Assuming a polymorphic site with two alleles $A$ and $a$, genotypes were encoded as $0=a a, 1=A a$, and $2=$ AA. Population attributable risk percentage (PAR\%) for the risk genotype ( $r$ 7574865T/T and T/G) was estimated by the formula

$$
P A R \%=P e(R R-1) /(P e[R R-1]+1),
$$


where Pe represents the risk genotype frequency in the population and $\mathrm{RR}$ represents relative risk of the risk genotype [23]. Given the low prevalence of SLE, Pe can be estimated based on the genotype frequencies in healthy controls and RR can be approximated by odds ratio (OR) for the risk genotypes.

\section{Results and Discussion}

The STAT4 gene is located on 2q32.2-q32.3 adjacently to STAT1 gene, and the region encompassing STAT1 and STAT4 spans approximately 180 kilobase pairs. In the first screening, 52 tag SNPs in the STAT1-STAT4 region, selected with an $r^{2}$ threshold of 0.9 based on the HapMap Phase II JPT data, were genotyped in 105 Japanese female SLE patients and 102 female healthy controls, and allele frequencies were compared between SLE patients and controls. A linkage disequilibrium (LD) plot and the results of the association study in the STAT1-STAT4 region are shown in Figure 1. Pairwise $r^{2}$ values between 52 tag SNPs were calculated using genotyping data from 102 healthy individuals.

Among the tag SNPs, rs10168266C >T, rs11889341C>T, and rs7574865G $>T$ were most significantly associated with SLE in the first screening $(P<0.01)$. Allele frequencies of rs10168266T, rs11889341T, and rs7574865T were significantly increased in SLE compared with healthy controls (Table 1 and Figure 1). These SNPs were located in the introns of STAT4 and in LD with each other. In contrast, significant association was not detected for SNPs in the STAT1 region $(P>$ 0.05).

To confirm the association detected in the first screening, additional patients and controls were genotyped for the three SNPs using the TaqMan SNP Genotyping Assay, and association was examined in 308 SLE patients and 306 healthy controls in total (Table 2). Significant deviation from HardyWeinberg equilibrium was not detected in healthy controls $(P$ $>0.05$ ). The rs7574865T allele, previously shown to be associated with SLE in Caucasians, was significantly increased in SLE patients $(46.3 \%)$ compared with controls $(33.5 \%, P=$ $4.9 \times 10^{-6}$, OR 1.71). The association was compatible with the dominant model, under which the OR was 2.19 (T/T + G/T versus $\mathrm{G} / \mathrm{G})$.

The SNPs rs11889341 and rs10168266 were in LD with rs7574865 ( $r^{2}: 0.57$ to $0.78, D^{\prime}: 0.91$ to 0.97$)$ and were also significantly associated with SLE (allele frequency: $P=6.6 \times$ $10^{-6}$ and $P=6.3 \times 10^{-6}$, respectively). Haplotype analysis revealed that the haplotype carrying rs10168266T, rs11889341T, and rs7574865T was significantly increased (SLE: $36.8 \%$, control: $24.3 \%, P=1.5 \times 10^{-6}$ ) whereas the haplotype carrying 10168266C, rs11889341C, and rs7574865G was significantly decreased in SLE (SLE: $52.7 \%$, control: $\left.65.0 \%, P=1.0 \times 10^{-5}\right)$. Logistic regression analysis demonstrated that the association of each SNP lost statistical significance when adjusted for genotype of the other
Figure 1

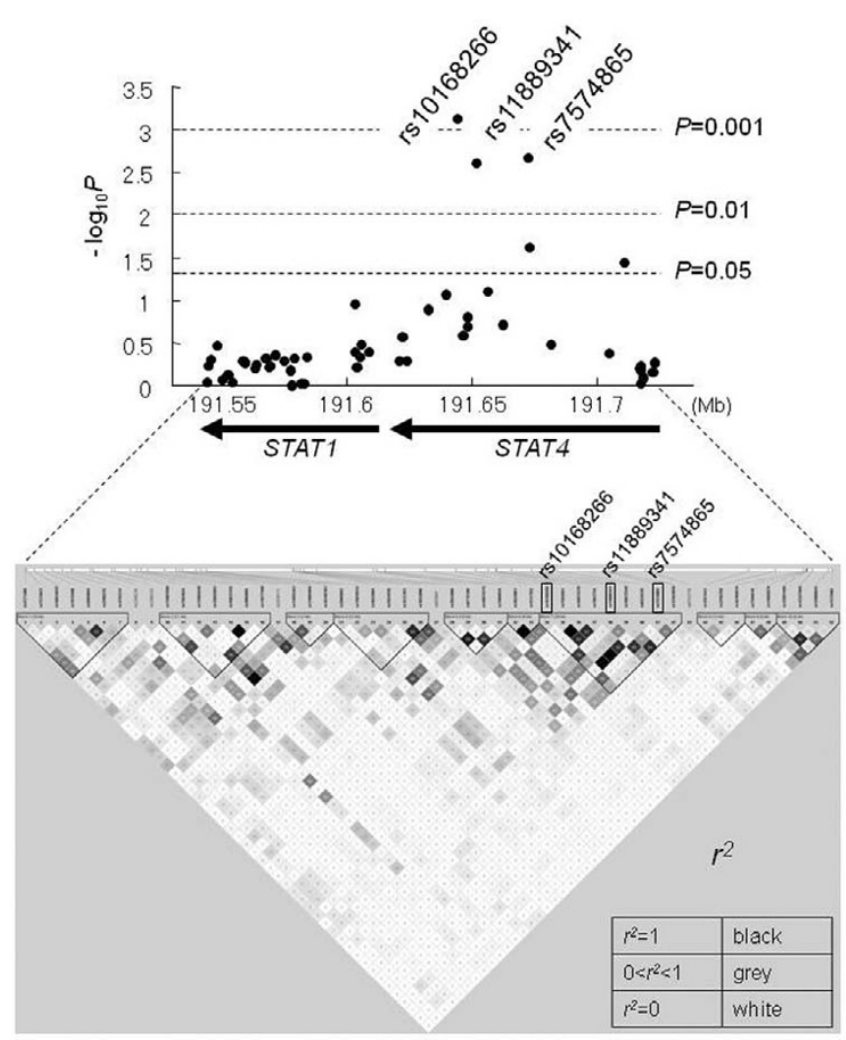

Linkage disequilibrium plot of the STAT1-STAT4 region in a Japanese population and first screening of 52 tag single nucleotide polymorphisms (SNPs). In the upper panel, $P$ values for differences in allele frequencies were calculated by chi-square test using two-by-two contingency tables. The $\log P$ value for each SNP is shown. In the lower panel, $r^{2}$ values calculated using Haploview version 4.0 software based on data from 102 healthy individuals are shown. The location and direction of transcription of STAT1 and STAT4 are indicated by arrows. SNPs rs10168266, rs11889341, and rs7574865 belong to the same haplotype block.

SNPs (Table 3). Thus, due to the strong LD, it was impossible to identify a single causative SNP among the three.

We next tested whether STAT4 rs7574865 was associated with phenotypes of SLE such as presence of nephritis, antidsDNA antibodies, and early age of onset (less than 20 years) as STAT4 genotype has been shown to be more strongly associated with subgroups of SLE with these phenotypes [10] (Table 4). Association of rs7574865 was observed both in SLE patients with nephritis $\left(P=1.0 \times 10^{-5}, \mathrm{OR}=1.85\right)$ and in those without nephritis $(P=0.0031, \mathrm{OR}=1.55)$. The association was stronger in SLE patients with nephritis, although the difference between SLE with and without nephritis (caseonly analysis) did not reach statistical significance. Similarly, rs7574865T was significantly increased in SLE patients with anti-dsDNA antibodies compared with healthy controls, whereas association was not detected in SLE patients without anti-dsDNA antibodies. The frequency of rs7574865T was slightly higher in the patients with an age of onset of less than 
Table 1

Minor allele frequencies and $\boldsymbol{P}$ values for 52 tag single nucleotide polymorphisms in the STAT1-STAT4 region in the first Screening

\begin{tabular}{|c|c|c|c|c|c|}
\hline \multirow[b]{2}{*}{ SNP } & \multirow[b]{2}{*}{ Chromosomal position ${ }^{\mathrm{a}}$} & \multicolumn{4}{|c|}{ Minor allele frequency } \\
\hline & & Minor allele & SLE patients $(n=105)$ & Controls $(n=102)$ & $P$ value \\
\hline rs3771300 & 191543841 & $\mathrm{C}$ & 0.305 & 0.309 & 0.929 \\
\hline rs7575823 & 191544163 & $A$ & 0.167 & 0.147 & 0.584 \\
\hline rs16824035 & 191545879 & $A$ & 0.057 & 0.074 & 0.500 \\
\hline rs1914408 & 191548221 & $A$ & 0.271 & 0.314 & 0.344 \\
\hline rs2066804 & 191550004 & A & 0.471 & 0.480 & 0.855 \\
\hline rs2280235 & 191552075 & A & 0.486 & 0.471 & 0.758 \\
\hline rs3755312 & 191554236 & $\mathrm{C}$ & 0.181 & 0.176 & 0.905 \\
\hline rs2280234 & 191558344 & $\mathrm{G}$ & 0.162 & 0.186 & 0.513 \\
\hline rs2280232 & 191559011 & $\mathrm{C}$ & 0.143 & 0.123 & 0.543 \\
\hline rs11887698 & 191563119 & $\mathrm{G}$ & 0.327 & 0.304 & 0.629 \\
\hline rs7562024 & 191563766 & $\mathrm{G}$ & 0.090 & 0.108 & 0.554 \\
\hline rs11904548 & 191567235 & A & 0.162 & 0.137 & 0.482 \\
\hline rs12693591 & 191568747 & $A$ & 0.257 & 0.235 & 0.606 \\
\hline rs16833155 & 191569622 & $A$ & 0.043 & 0.054 & 0.600 \\
\hline rs2066805 & 191571146 & $\mathrm{G}$ & 0.038 & 0.054 & 0.442 \\
\hline rs11677408 & 191574860 & $A$ & 0.129 & 0.108 & 0.514 \\
\hline rs2030171 & 191577408 & $\mathrm{G}$ & 0.329 & 0.309 & 0.666 \\
\hline rs11693463 & 191578156 & $\mathrm{G}$ & 0.195 & 0.196 & 0.983 \\
\hline rs11885069 & 191578869 & $A$ & 0.162 & 0.137 & 0.482 \\
\hline rs10199181 & 191581798 & $\mathrm{~T}$ & 0.267 & 0.265 & 0.964 \\
\hline rs2066802 & 191582912 & $\mathrm{G}$ & 0.257 & 0.255 & 0.956 \\
\hline rs13029532 & 191584146 & $\mathrm{C}$ & 0.082 & 0.103 & 0.457 \\
\hline rs3024904 & 191603447 & $A$ & 0.112 & 0.141 & 0.400 \\
\hline rs3024936 & 191603621 & $\mathrm{C}$ & 0.024 & 0.055 & 0.112 \\
\hline rs 1517351 & 191604290 & C & 0.490 & 0.464 & 0.602 \\
\hline rs3024896 & 191604961 & $A$ & 0.448 & 0.412 & 0.461 \\
\hline rs925847 & 191605785 & $A$ & 0.538 & 0.490 & 0.330 \\
\hline rs3024886 & 191608694 & $A$ & 0.457 & 0.417 & 0.407 \\
\hline rs6715106 & 191621279 & $\mathrm{G}$ & 0.067 & 0.083 & 0.520 \\
\hline rs16833215 & 191622044 & $\mathrm{G}$ & 0.495 & 0.441 & 0.270 \\
\hline rs1400654 & 191623918 & $T$ & 0.066 & 0.083 & 0.524 \\
\hline rs3024861 & 191632851 & $\mathrm{~T}$ & 0.471 & 0.397 & 0.127 \\
\hline rs1517352 & 191639709 & $A$ & 0.481 & 0.397 & 0.086 \\
\hline rs10168266 & 191644049 & $A$ & 0.400 & 0.245 & $7.6 \times 10^{-4}$ \\
\hline rs7594501 & 191646845 & A & 0.114 & 0.152 & 0.250 \\
\hline rs16833239 & 191648505 & $A$ & 0.110 & 0.152 & 0.200 \\
\hline rs7601754 & 191648696 & $G$ & 0.129 & 0.178 & 0.162 \\
\hline
\end{tabular}


Table 1 (Continued)

\begin{tabular}{|c|c|c|c|c|c|}
\hline rs11889341 & 191651987 & $A$ & 0.443 & 0.299 & 0.003 \\
\hline rs16833249 & 191656517 & $\mathrm{G}$ & 0.567 & 0.480 & 0.079 \\
\hline rs6434435 & 191662109 & $A$ & 0.099 & 0.141 & 0.192 \\
\hline rs7574865 & 191672878 & $A$ & 0.471 & 0.324 & 0.002 \\
\hline rs12463658 & 191673589 & $\mathrm{C}$ & 0.581 & 0.471 & 0.025 \\
\hline rs6752770 & 191681808 & $\mathrm{G}$ & 0.205 & 0.245 & 0.326 \\
\hline rs1551443 & 191704763 & $A$ & 0.238 & 0.206 & 0.431 \\
\hline rs2356350 & 191710783 & $\mathrm{G}$ & 0.510 & 0.407 & 0.036 \\
\hline rs10189819 & 191716994 & $\mathrm{G}$ & 0.133 & 0.118 & 0.630 \\
\hline rs7596818 & 191717555 & $A$ & 0.320 & 0.295 & 0.580 \\
\hline rs11685878 & 191717700 & $A$ & 0.429 & 0.431 & 0.954 \\
\hline rs12991409 & 191717762 & $\mathrm{G}$ & 0.100 & 0.113 & 0.674 \\
\hline rs12327969 & 191719016 & $\mathrm{G}$ & 0.390 & 0.402 & 0.811 \\
\hline rs12988825 & 191722509 & $\mathrm{C}$ & 0.119 & 0.132 & 0.683 \\
\hline rs7572482 & 191723317 & G & 0.490 & 0.461 & 0.545 \\
\hline
\end{tabular}

aChromosomal positions are shown according to the National Center for Biotechnology Information (Bethesda, MD, USA) reference assembly. SLE, systemic lupus erythematosus; SNP, single nucleotide polymorphism; STAT, signal transducers and activators of transcription.

20 years as compared with greater than or equal to 20 years, although the difference was not statistically significant. These tendencies are consistent with those reported in Caucasians [10]. These interpretations were not affected when the significance level was corrected for the number of comparisons (three phenotypes).

To evaluate the epidemiological significance of STAT4 polymorphism in the genetic background of SLE in the Japanese population, we estimated the PAR\% in Japanese persons and Caucasians using our present data and previously reported data $[8,11,12]$ (Table 5). Because the frequency and OR of the risk genotype of rs7574865 were greater in the Japanese population than those of North Americans of European descent [8], PAR\% in the Japanese population (40.2\%) was much higher than that of the latter (19.5\%). A similarly high PAR\% was observed in two of the three Japanese case-control series reported by Kobayashi and colleagues [12] and in Colombians [11]. Because PAR\% may be affected by the difference in the method of ascertainment of each study, this comparison may not be completely valid. Nevertheless, these observations suggested that the contribution of STAT4 for SLE is greater in the Japanese population as compared with the Americans of European descent.

At this point, molecular mechanisms that account for the association of STAT4 intron SNPs with SLE remain unclear. Studies with lupus model mice lacking Stat4 showed conflicting results. Stat4 deficiency reduced nephritis and autoantibody production in B6.NZM.Sle1.Sle2.S/e3 mice [24]. In contrast,
Stat4-deficient NZM (New Zealand mixed) mice developed accelerated nephritis and increased mortality in the absence of high levels of autoantibodies [25]. STAT4 has been shown to be involved in the induction of IFN $\gamma$, differentiation of Th1 and Th17 cells, and signal transduction from type I IFN receptors [15]. Th1 cytokines, especially IFN $\gamma$, have been shown to play a role in the pathogenesis of lupus nephritis [26]. Recently, T cells from SLE patients were shown to produce excessive amounts of IFN $\gamma$ upon stimulation [27]. These observations may implicate the role of STAT4 SNPs in IFN $\gamma$ production.

The role of type I IFNs in SLE has been established [1]. Elevated serum type I IFN levels and expression of IFN-inducible genes in peripheral mononuclear cells were reported in SLE $[28,29]$. The association of IRF5, which induces type I IFNs, with SLE has been established [2-6]. STAT4 is activated by type I IFN as well as IL-12 signals and produces IFN $\gamma$ [15]. Thus, STAT4 may also contribute to SLE as a component of the type I IFN signal pathway. Furthermore, STAT4 has been reported to transduce IL-12 signals to induce IFN $\gamma$ production in $B$ cells [30].

It is interesting to note that significant association of STAT4 was not observed in SLE patients without anti-dsDNA antibodies (Table 4). It would have been interesting to examine the effect of the genotype on the levels, rather than presence or absence, of anti-dsDNA antibody However, because the antibody levels fluctuate in association with disease activity and treatment, association with the genotype should be examined 
Arthritis Research \& Therapy Vol 10 No 5 Kawasaki et al.

Table 2

Association of STAT4 single nucleotide polymorphisms rs10168266, rs11889341, and rs7574865 with systemic lupus erythematosus

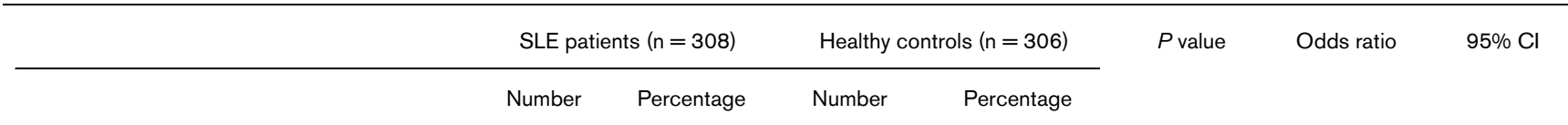

rs10168266

Genotype frequency

$\begin{array}{lccccccc}\mathrm{C} / \mathrm{C} & 118 & 38.3 & 166 & 54.2 & & & \\ \mathrm{C} / \mathrm{T} & 147 & 47.7 & 122 & 39.9 & 7.5 \times 10^{-5 a} & 1.91 & 1.39-2.63^{\mathrm{a}} \\ \mathrm{T} / \mathrm{T} & 43 & 14.0 & 18 & 5.9 & & \end{array}$

Allele frequency

$\mathrm{T}$

233

$37.8 \quad 158$

$6.3 \times 10^{-6} \quad 1.75$

$1.37-2.23$

rs11889341

Genotype frequency

$\begin{array}{lccccccc}\mathrm{C} / \mathrm{C} & 99 & 32.1 & 153 & 50.0 & & & \\ \mathrm{C} / \mathrm{T} & 161 & 52.3 & 126 & 41.2 & 6.9 \times 10^{-6 \mathrm{a}} & 2.11 & 1.52-2.92^{\mathrm{a}} \\ \mathrm{T} / \mathrm{T} & 48 & 15.6 & 27 & 8.8 & & \end{array}$

Allele frequency

T

257

$41.7 \quad 180$

29.4

$6.6 \times 10^{-6}$

1.72

$1.36-2.17$

rs7574865

Genotype frequency

$\begin{array}{cccccccc}\mathrm{G} / \mathrm{G} & 80 & 26.0 & 133 & 43.5 & & & \\ \mathrm{G} / \mathrm{T} & 171 & 55.5 & 141 & 46.1 & 5.3 \times 10^{-6 a} & 2.19 & 1.56-3.07^{\mathrm{a}} \\ \mathrm{T} / \mathrm{T} & 57 & 18.5 & 32 & 10.5 & & \end{array}$

Allele frequency

$T$

285

$46.3 \quad 205$

33.5

$4.9 \times 10^{-6}$

1.71

$1.36-2.15$

rs10168266/rs11889341/rs7574865

Haplotype frequency

$\begin{array}{lccc}\text { CCG } & 52.7 & 65.0 & 1.0 \times 10^{-5 b} \\ \text { TTT } & 36.8 & 24.3 & 1.5 \times 10^{-6 b} \\ \text { CCT } & 4.9 & 5.1 & \text { NS }^{b} \\ \text { CTT } & 4.6 & 4.1 & \text { NS b }^{\mathrm{b}}\end{array}$

a $P$ values, odds ratios, and $95 \%$ confidence intervals $(\mathrm{Cls})$ were calculated under the dominant model for the minor allele. b $P$ values were calculated by permutation test using Haploview version 4.0 software. Ten million permutations were performed. NS, not significant; SLE, systemic lupus erythematosus; STAT, signal transducers and activators of transcription.

Table 3

Logistic regression analysis of the systemic lupus erythematosus-associated single nucleotide polymorphisms in STAT4

\begin{tabular}{lcccc}
\hline SNP & & \multicolumn{3}{c}{ Padjusted for } \\
\hline rs10168266 & $P$ value & rs10168266 & rs1 1889341 & rs7574865 \\
rs11889341 & $4.9 \times 10^{-6}$ & NA & 0.272 & 0.146 \\
rs7574865 & $4.7 \times 10^{-6}$ & 0.251 & NA & 0.388 \\
\end{tabular}

NA, not applicable; SNP, single nucleotide polymorphism; STAT, signal transducers and activators of transcription. 
Association of STAT4 rs7574865 with characteristics of systemic lupus erythematosus such as nephritis, age of onset, and antidouble-stranded-DNA antibodies

\begin{tabular}{|c|c|c|c|c|}
\hline & \multicolumn{2}{|c|}{ T allele } & \multirow[t]{2}{*}{$P$ value } & \multirow[t]{2}{*}{ Odds ratio $(95 \% \mathrm{Cl})$} \\
\hline & Number & Frequency & & \\
\hline \multicolumn{5}{|l|}{ Case subgroup versus healthy controls } \\
\hline \multicolumn{5}{|l|}{ Nephritis } \\
\hline Present $(n=165)$ & 159 & $48.2 \%$ & $1.0 \times 10^{-5}$ & $1.85(1.41-2.42)$ \\
\hline Absent $(n=138)$ & 121 & $43.8 \%$ & 0.0031 & $1.55(1.16-2.07)$ \\
\hline \multicolumn{5}{|l|}{ Anti-double-stranded DNA antibodies } \\
\hline Present $(n=130)$ & 125 & $48.1 \%$ & $4.9 \times 10^{-5}$ & $1.84(1.37-2.47)$ \\
\hline Absent $(n=34)$ & 24 & $35.3 \%$ & NS & $1.08(0.64-1.83)$ \\
\hline \multicolumn{5}{|l|}{ Age of onset } \\
\hline$<20$ years $(n=86)$ & 83 & $48.3 \%$ & $3.9 \times 10^{-4}$ & $1.85(1.32-2.60)$ \\
\hline$\geq 20$ years $(n=198)$ & 180 & $45.5 \%$ & $1.4 \times 10^{-4}$ & $1.65(1.28-2.14)$ \\
\hline Healthy controls $(n=306)$ & 205 & $33.5 \%$ & & \\
\hline \multicolumn{5}{|c|}{ Case-only (present versus absent or $<20$ versus $\geq 20$ years) } \\
\hline Nephritis & & & NS & $1.19(0.86-1.64)$ \\
\hline Anti-double-stranded DNA antibodies & & & NS & $1.70(0.98-2.95)$ \\
\hline Age of onset & & & NS & $1.12(0.78-1.60)$ \\
\hline
\end{tabular}

Systemic lupus erythematosus (SLE) patients were stratified into subgroups according to the presence or absence of nephritis, anti-double-stranded DNA (antidsDNA) antibodies, and age of onset ( $<20$ or $\geq 20$ years). Allele frequencies were compared between each SLE subgroup and healthy controls as well as between SLE subgroups (case-only analysis, nephritis present versus absent, anti-dsDNA antibodies present versus absent, and age of onset $<20$ versus $\geq 20$ years). Cl, confidence interval; NS, not significant; STAT, signal transducers and activators of transcription.

using the lifetime highest anti-dsDNA antibody level of each patient. Such data were not available for this study, and we hope that we can address this issue in the future.

Most of these observations imply that STAT4 risk genotype may be associated with an elevated expression level and/or function of STAT4 protein. A recent study reported that the STAT4 risk allele was associated with overexpression of STAT4 in osteoblasts but not in B cells [13]. To address the significance of such findings, it will be necessary to examine the effect of this genotype on the expression levels and splicing isoforms in $\mathrm{T}$ and $\mathrm{B}$ cells.

\section{Conclusion}

Through comprehensive association analysis of the STAT1STAT4 region with SLE in the Japanese population, we demonstrated that the same STAT4 risk allele in Caucasians was strongly associated with susceptibility to SLE in the Japanese population. In contrast, evidence for an association of STAT1 SNPs was not observed. The contribution of STAT4 SNPs to

Table 5

Population attributable risk percentage of STAT4 rs7574865 under the dominant model

\begin{tabular}{|c|c|c|c|}
\hline Population [reference] & Frequency of $(T / T+T / G)$ & Odds ratio & PAR\% \\
\hline Japanese (this study) & $56.5 \%$ & 2.19 & $40.2 \%$ \\
\hline Japanese (TWMU) [12] & $52.3 \%$ & 1.81 & $29.7 \%$ \\
\hline Japanese (RIKEN) [12] & $51.7 \%$ & 1.51 & $20.8 \%$ \\
\hline Japanese (Tokushima/Fukuoka) [12] & $51.9 \%$ & 2.07 & $35.8 \%$ \\
\hline Americans of European descent [8] & $41.2 \%$ & 1.59 & $19.5 \%$ \\
\hline Colombians [11] & $51.7 \%$ & 1.87 & $31.0 \%$ \\
\hline
\end{tabular}

PAR\%, population attributable risk percentage; RIKEN, The Institute of Physical and Chemical Research, Wako, Japan; STAT, signal transducers and activators of transcription; TWMU, Tokyo Women's Medical University, Tokyo, Japan. 
the genetic background of SLE may be greater in the Japanese population than in Americans of European descent.

\section{Competing interests}

RRG, GH, and TWB are employees of and hold stocks or shares in Genentech, Inc. (South San Francisco, CA, USA). The other authors declare that they have no competing interests.

\section{Authors' contributions}

AK participated in the study design, carried out all genotyping and statistical analyses, and wrote the manuscript. II, KH, MK, and TA participated in the first screening using Illumina GoldenGate assay (with AK), including tag SNP selection, genotyping, and statistical analysis. JO carried out statistical analysis with $\mathrm{AK}$ and helped in the manuscript preparation. $\mathrm{TH}$, DG, IM, SI, AT, YT, HH, and TS recruited Japanese patients with SLE and collected clinical information. RRG and GH provided Caucasian data. NT conceived of the study, together with TWB, and participated in its design and coordination, recruited patients and controls, and helped in the manuscript preparation. All authors read and approved the final manuscript.

\section{Acknowledgements}

This work was supported by KAKENHI (Grant-in-Aid for Scientific Research) (B) from the Japan Society for the Promotion of Science; KAKENHI on the Priority Area 'Applied Genomics' from the Ministry of Education, Culture, Sports, Science and Technology of Japan; and grants from the Ministry of Health, Labour and Welfare of Japan; the Japan Rheumatism Foundation; and the Naito Foundation.

\section{References}

1. Kyogoku C, Tsuchiya N: A compass that points to lupus: genetic studies on type I interferon pathway. Genes Immun 2007, 8:445-455.

2. Kawasaki A, Kyogoku C, Ohashi J, Miyashita R, Hikami K, Kusaoi M, Tokunaga K, Takasaki Y, Hashimoto H, Behrens TW, Tsuchiya $\mathrm{N}$ : Association of IRF5 polymorphisms with systemic lupus erythematosus in a Japanese population: support for a crucial role of intron 1 polymorphisms. Arthritis Rheum 2008, 58:826-834.

3. Sigurdsson S, Nordmark G, Göring HH, Lindroos K, Wiman AC, Sturfelt G, Jönsen A, Rantapää-Dahlqvist S, Möller B, Kere J, Koskenmies S, Widén E, Eloranta ML, Julkunen H, Kristjansdottir $\mathrm{H}$, Steinsson K, Alm G, Rönnblom L, Syvänen AC: Polymorphisms in the tyrosine kinase 2 and interferon regulatory factor 5 genes are associated with systemic lupus erythematosus. Am J Hum Genet 2005, 76:528-537.

4. Graham RR, Kyogoku C, Sigurdsson S, Vlasova IA, Davies LR, Baechler EC, Plenge RM, Koeuth T, Ortmann WA, Hom G, Bauer JW, Gillett C, Burtt N, Cunninghame Graham DS, Onofrio R, Petri M, Gunnarsson I, Svenungsson E, Rönnblom L, Nordmark G, Gregersen PK, Moser K, Gaffney PM, Criswell LA, Vyse TJ, Syvänen AC, Bohjanen PR, Daly MJ, Behrens TW, Altshuler D: Three functional variants of IFN regulatory factor 5 (IRF5) define risk and protective haplotypes for human lupus. Proc Natl Acad Sci USA 2007, 104:6758-6763.

5. Ferreiro-Neira I, Calaza M, Alonso-Perez E, Marchini M, Scorza R, Sebastiani GD, Blanco FJ, Rego I, Pullmann R Jr, Pullmann R, Kallenberg CG, Bijl M, Skopouli FN, Mavromati M, Migliaresi S, Barizzone N, Ruzickova S, Dostal C, Schmidt RE, Witte T, Papasteriades C, Kappou-Rigatou I, Endreffy E, Kovacs A, Ordi-Ros J, Balada E, Carreira P, Gomez-Reino JJ, Gonzalez A: Opposed independent effects and epistasis in the complex association of IRF5 to SLE. Genes Immun 2007, 8:429-438.

6. Kelly JA, Kelley JM, Kaufman KM, Kilpatrick J, Bruner GR, Merrill JT, James JA, Frank SG, Reams E, Brown EE, Gibson AW, Marion MC, Langefeld CD, Li OZ, Karp DR, Wakeland EK, Petri M, Ramsey-Goldman R, Reveille JD, Vilá LM, Alarcón GS, Kimberly RP, Harley JB, Edberg JC: Interferon regulatory factor-5 is genetically associated with systemic lupus erythematosus in African Americans. Genes Immun 2008, 9:187-194.

7. Remmers EF, Plenge RM, Lee AT, Graham RR, Hom G, Behrens TW, de Bakker PI, Le JM, Lee HS, Batliwalla F, Li W, Masters SL, Booty MG, Carulli JP, Padyukov L, Alfredsson L, Klareskog L, Chen WV, Amos Cl, Criswell LA, Seldin MF, Kastner DL, Gregersen PK: STAT4 and the risk of rheumatoid arthritis and systemic lupus erythematosus. N Engl J Med 2007, 357:977-986.

8. Hom G, Graham RR, Modrek B, Taylor KE, Ortmann W, Garnier S Lee AT, Chung SA, Ferreira RC, Pant PV, Ballinger DG, Kosoy R, Demirci FY, Kamboh MI, Kao AH, Tian C, Gunnarsson I, Bengtsson AA, Rantapää-Dahlqvist S, Petri M, Manzi S, Seldin MF, Rönnblom L, Syvänen AC, Criswell LA, Gregersen PK, Behrens TW: Association of systemic lupus erythematosus with C8orf13-BLK and ITGAM-ITGAX. N Engl J Med 2008, 358:900-909.

9. International Consortium for Systemic Lupus Erythematosus Genetics (SLEGEN), Harley JB, Alarcón-Riquelme ME, Criswell LA, Jacob CO, Kimberly RP, Moser KL, Tsao BP, Vyse TJ, Langefeld CD: Genome-wide association scan in women with systemic lupus erythematosus identifies susceptibility variants in ITGAM, PXK, KIAA1542 and other loci. Nat Genet 2008, 40:204-210.

10. Taylor KE, Remmers EF, Lee AT, Ortmann WA, Plenge RM, Tian C, Chung SA, Nititham J, Hom G, Kao AH, Demirci FY, Kamboh MI, Petri M, Manzi S, Kastner DL, Seldin MF, Gregersen PK, Behrens TW, Criswell LA: Specificity of the STAT4 genetic association for severe disease manifestations of systemic lupus erythematosus. PLoS Genet 2008, 4:e1000084.

11. Palomino-Morales RJ, Rojas-Villarraga A, González Cl, Ramírez G, Anaya JM, Martín J: STAT4 but not TRAF1/C5 variants influence the risk of developing rheumatoid arthritis and systemic lupus erythematosus in Colombians. Genes Immun 2008, 9:379-382.

12. Kobayashi S, Ikari K, Kaneko H, Kochi Y, Yamamoto K, Shimane K, Nakamura Y, Toyama Y, Mochizuki T, Tsukahara S, Kawaguchi $Y$, Terai C, Hara M, Tomatsu T, Yamanaka H, Horiuchi T, Tao K, Yasutomo K, Hamada D, Yasui N, Inoue H, Itakura M, Okamoto $\mathrm{H}$ Kamatani N, Momohara S: Association of STAT4 with susceptibility to rheumatoid arthritis and systemic lupus erythematosus in the Japanese population. Arthritis Rheum 2008, 58:1940-1946.

13. Sigurdsson S, Nordmark G, Garnier S, Grundberg E, Kwan T, Nilsson O, Eloranta M-L, Gunnarsson I, Svenungsson E, Sturfelt G, Bengtsson $A A$, Jönsen $A$, Truedsson $L$, Rantapää-Dahlqvist $S$, Eriksson C, Alm G, Göring HHH, Pastinen T, Syvänen A-C, Rönnblom L: A common STAT4 risk haplotype for systemic lupus erythematosus is over-expressed, correlates with anti-dsDNA production and shows additive effects with two IRF5 risk alleles. Hum Mol Genet 2008, 17:2868-2876.

14. Korman BD, Alba MI, Le JM, Alevizos I, Smith JA, Nikolov NP, Kastner DL, Remmers EF, Illei GG: Variant form of STAT4 is associated with primary Sjögren's syndrome. Genes Immun 2008, 9:267-270.

15. Watford WT, Hissong BD, Bream JH, Kanno Y, Muul L, O'Shea JJ: Signaling by IL-12 and IL-23 and the immunoregulatory roles of STAT4. Immunol Rev 2004, 202:139-156.

16. Nguyen KB, Watford WT, Salomon R, Hofmann SR, Pien GC, Morinobu A, Gadina M, O'Shea JJ, Biron CA: Critical role for STAT4 activation by type 1 interferons in the interferongamma response to viral infection. Science 2002, 297:2063-2066.

17. Mathur AN, Chang HC, Zisoulis DG, Stritesky GL, Yu Q, O'Malley JT, Kapur R, Levy DE, Kansas GS, Kaplan MH: Stat3 and Stat4 direct development of IL-17-secreting Th cells. J Immunol 2007, 178:4901-4907.

18. Hoey T, Zhang S, Schmidt N, Yu Q, Ramchandani S, Xu X, Naeger LK, Sun YL, Kaplan MH: Distinct requirements for the naturally occurring splice forms Stat $4 \alpha$ and Stat $4 \beta$ in IL-12 responses. $E M B O$ J 2003, 22:4237-4248. 
19. Takeda K, Akira S: STAT family of transcription factors in cytokine-mediated biological responses. Cytokine Growth Factor Rev 2000, 11:199-207.

20. Baechler EC, Gregersen PK, Behrens TW: The emerging role of interferon in human systemic lupus erythematosus. Curr Opin Immunol 2004, 16:801-807.

21. Dong J, Wang QX, Zhou CY, Ma XF, Zhang YC: Activation of the STAT1 signalling pathway in lupus nephritis in MRL/Ipr mice. Lupus 2007, 16:101-109.

22. Hochberg MC: Updating the American College of Rheumatology revised criteria for the classification of systemic lupus erythematosus. Arthritis Rheum 1997, 40:1725.

23. Schildkraut JM: Examining complex genetic interactions. In Approach to Gene Mapping in Complex Human Diseases Edited by: Haines JL, Pericak-Vance MA. New York, NY: Wiley-Liss; 1998:379-410

24. Xu Z, Duan B, Croker BP, Morel L: STAT4 deficiency reduces autoantibody production and glomerulonephritis in a mouse model of lupus. Clin Immunol 2006, 120:189-198.

25. Jacob CO, Zang S, Li L, Ciobanu V, Quismorio F, Mizutani A, Satoh M, Koss M: Pivotal role of Stat4 and Stat6 in the pathogenesis of the lupus-like disease in the New Zealand mixed 2328 mice. $J$ Immunol 2003, 171:1564-1571.

26. Akahoshi $M$, Nakashima $H$, Tanaka $Y$, Kohsaka T, Nagano $S$, Ohgami E, Arinobu Y, Yamaoka K, Niiro H, Shinozaki M, Hirakata $H$, Horiuchi T, Otsuka T, Niho $Y$ : Th1/Th2 balance of peripheral T helper cells in systemic lupus erythematosus. Arthritis Rheum 1999, 42:1644-1648.

27. Harigai M, Kawamoto M, Hara M, Kubota T, Kamatani N, Miyasaka $\mathrm{N}$ : Excessive production of IFN- $\gamma$ in patients with systemic lupus erythematosus and its contribution to induction of $B$ lymphocyte stimulator/B cell-activating factor/TNF ligand superfamily-13B. J Immunol 2008, 181:2211-2219.

28. Crow MK: Interferon- $\alpha$ : a new target for therapy in systemic lupus erythematosus? Arthritis Rheum 2003, 48:2396-2401.

29. Baechler EC, Batliwalla FM, Karypis G, Gaffney PM, Ortmann WA, Espe KJ, Shark KB, Grande WJ, Hughes KM, Kapur V, Gregersen PK, Behrens TW: Interferon-inducible gene expression signature in peripheral blood cells of patients with severe lupus. Proc Natl Acad Sci USA 2003, 100:2610-2615.

30. Durali D, de Goër de Herve M-G, Giron-Michel J, Azzarone B, Delfraissy J-F, Taoufik $Y$ : In human $B$ cells, IL-12 triggers a cascade of molecular events similar to Th1 commitment. Blood 2003, 102:4084-4089. 